\title{
Redistribution through Charity and Optimal Taxation when People are Concerned with Social Status ${ }^{*}$
}

\author{
Thomas Aronsson a \\ Olof Johansson-Stenman b \\ Ronald Wendner ${ }^{\mathrm{c}}$ \\ a Department of Economics, Umeå School of Business and Economics, Umeå University, \\ Sweden \\ $\mathrm{b}$ Department of Economics, School of Business, Economics and Law, University of \\ Gothenburg, Sweden \\ c Department of Economics, University of Graz, Austria
}

January 2016

\begin{abstract}
This paper deals with tax policy responses to charitable giving based on a model of optimal redistributive income taxation. The major contribution is the simultaneous treatment of (i) warm-glow and stigma effects of charitable donations; (ii) that the warm glow of giving and stigma of receiving charity may to some extent depend on relative comparisons; and (iii) that people are also concerned with their relative consumption more generally. Whether charity should be taxed or supported turns out to largely depend on the relative strengths of the warm glow of giving and the stigma of receiving charity, respectively, and on the positional externalities caused by charitable donations. In addition, imposing stigma on the mimicker (via a relaxation of the self-selection constraint) strengthens the case for subsidizing charity. We also consider a case where the government is unable to target the charitable giving through a direct tax instrument, and examine how the optimal marginal income tax structure is adjusted in response to charitable giving.
\end{abstract}

Keywords: Conspicuous consumption, conspicuous charitable giving, optimal income taxation, warm glow, stigma

JEL Classification: D03, D62, H21, H23

\footnotetext{
* Research grants from the Bank of Sweden Tercentenary Foundation, the Swedish Council for Working Life and Social Research, and the Swedish Tax Agency (all of them through project number RS10-1319:1) are gratefully acknowledged.
} 


\section{Introduction}

Redistribution from the rich to the poor is a core governmental task in modern societies. In many countries, private charity also plays a non-negligible role in this redistribution. Since redistribution through the tax system is normally associated with social costs, due to incentive effects, one may wonder whether such effects motivate governmental support of private charity. Indeed, private charity is explicitly supported in many countries, including the U.S., e.g., through tax deduction for charitable giving, effectively implying that charity is subsidized relative to private consumption. Under which conditions are there good reasons for this? The present paper tries to answer this question by analyzing optimal tax policy responses to private charity, and thus examines the conditions for when charitable giving should be taxed or subsidized at the margin, and also how the policy rules for optimal marginal income taxation should be adjusted.

While many earlier papers have made important contributions to the issue of optimal taxation and charity, ${ }^{1}$ the framework adopted here is in many ways richer than the ones examined previously. First, we follow much of the traditional theory of charitable giving in assuming that individuals experience a warm glow from donating (Andreoni, 1989, 1990). Second, we follow empirical evidence in assuming that charitable giving is partly driven by status considerations, and that people thus derive utility from giving more than others. Third, we acknowledge the vast empirical evidence showing that people are also concerned with their relative private consumption more generally, i.e., they prefer to consume more and dislike consuming less than others. Finally, based on sociological literature we assume that charity recipients suffer from social stigma in the sense that they derive disutility from receiving charity for a given consumption level. The present paper brings all these elements together in a model of optimal nonlinear income taxation. It turns out that assumptions regarding warm glow of giving and stigma of receiving charity, respectively, are key to understanding whether charity should be taxed or supported.

In 2014, total U.S. charitable giving amounted to more than $\$ 358$ billion, or about 2.1 percent of GDP (Giving USA, 2015), which is clearly a substantial amount. Why do people give so much to charity? In addition to altruism and warm glow, there is evidence suggesting a status motive behind charitable giving. For example, Glazer and Konrad (1996) collect empirical data on charitable giving where public donation records report the name and the donation

\footnotetext{
${ }^{1}$ See e.g. Feldstein (1980), Warr (1982), Roberts (1987), Kaplow (1995, 1998), Saez (2004), and Diamond (2006).
} 
category (\$ range of donations) of the respective donor, and find that the mean donation in each category is close to its lower bound, as predicted by their theory of donations as status signals. Harbaugh (1998a, b) investigates the prestige motive for charitable giving and demonstrates that donations significantly increase when a charity switches from no-reporting of donations to exact-reporting. Results in the spirit of those two papers are also reported by Cartwright and Patel (2013). Similarly, in a series of lab experiments, Reinstein and Riener (2012) show that donors tend to donate more if their donations are reported than if they are anonymous.

Concerns about social status through comparisons with other people's behavior are typically not isolated to specific choices such as charitable giving. Instead, a vast empirical literature on relative income and consumption suggests that such comparisons are also important for income formation and consumption more generally. Happiness and questionnaire-based research repeatedly finds that people derive utility from their relative income and consumption compared with referent others; see, e.g., Johansson-Stenman et al. (2002), Solnick and Hemenway (2005), and Carlsson et al. (2007) for evidence based on questionnaire-experimental research, and Easterlin (2001), Blanchflower and Oswald (2004), Ferrer-i-Carbonell (2005), and Clark and Senik (2010) for evidence based on happiness research. This is clearly relevant in the context of charitable giving, since relative consumption comparisons are likely to influence decisions to donate and therefore also the optimal policy responses to charitable giving. Accordingly, our model will take such comparisons into account as well.

While poverty in itself can be associated with shame, as noted by Sen $(1983,1999)$, and there is also ample evidence, not least from literatures in social psychology and sociology, of social stigma related to receiving charity and targeted welfare benefits. There is also an economics literature on implications of social stigma. For example, Moffitt (1983) defines welfare stigma as the corresponding lack of self-respect due to an inability to support oneself, whereas Besley and Coate (1992) and Kleven and Kopczuk (2011) analyze how social stigma may matter for public policy. Moreover, there is a robust finding in happiness research that unemployment tends to imply reduced happiness, also when correcting for the income loss that unemployment gives rise to (e.g., Clark and Oswald, 1994; Blanchflower and Oswald, 2004). Note that this is at odds with the assumptions normally made in economics, since unemployment implies more leisure, but is consistent with the idea of a stigma associated 
with living on welfare. Based on these literatures, it seems logical to allow for the possibility that potential charity recipients prefer redistribution through the tax system over receiving the same funds through charitable donations.

Several earlier studies have analyzed optimal tax policy responses to charitable giving. Feldstein (1980), Roberts (1987), Saez (2004), and Diamond (2006) have in different settings examined optimal tax policy in economies where charitable giving contributes to a public good. The task of the government is then to simultaneously decide how much of the public good it should provide itself and the extent to which it should support private contributions to the public good through tax deduction possibilities. The present paper, in contrast, focuses on charitable giving from the rich to the poor, or more specifically in our model setup from highability to low-ability individuals, and assumes that the government redistributes through nonlinear taxation subject to a self-selection constraint. ${ }^{2}$ Moreover, although Diamond (2006) does also consider a model with nonlinear taxation, he focuses on contributions to a public good (with and without a warm-glow preference) and pays no attention to social comparisons or the stigma that charity recipients may experience.

Since social comparisons play an important role in the analysis carried out below, our paper also bears a close relationship to earlier research on relative consumption and optimal taxation. A major issue in this line of research has been to examine how relative consumption comparisons among consumers affect the structure of marginal income taxation and/or commodity taxation, which a number of studies have addressed based on various models and tax instruments (e.g., Boskin and Sheshinski, 1978; Layard, 1980; Oswald, 1983; Dupor and Liu, 2003; Ljungqvist and Uhlig, 2000; Aronsson and Johansson-Stenman, 2008, 2010, 2014; Wendner and Golder, 2008; and Eckerstorfer and Wendner,2013). It is now well established that an externality caused by such comparisons calls for a significant corrective element in the tax system, and it is also clear how this Pigouvian component is modified in economies with heterogeneous consumers due to the incentive constraint faced by policy makers. Yet, none of the aforementioned studies on optimal tax policy address the consequences of positional concerns with respect to charitable giving.

To our knowledge, the only earlier study dealing with policy implications of conspicuous charitable giving is that by Blumkin and Sadka (2007a). They consider an innovative model

\footnotetext{
${ }^{2}$ See Auten et al. (2002) and Clotfelter $(1992,2014)$ for extensive empirical analyses of the redistributive effects of charity.
} 
in which charitable giving signals wealth, while neglecting the possible "warm glow" motive for charitable giving ${ }^{3}$ as well as stigma effects and status related to relative consumption. In their study, the policy maker uses linear income taxation and a linear tax/subsidy on charity to redistribute income and correct for the externality (implied by charitable giving). By analyzing the welfare effects of introducing a tax on charitable giving under an optimal income tax, they are able to conclude that the optimal tax on charitable giving is non-negative due to the negative externalities that such giving gives rise to in their model.

The novel contribution of the present paper is the simultaneous treatment of warm-glow, conspicuous-giving, and stigma effects of charitable donations in the study of optimal nonlinear income taxation, and that the analysis is carried out in a framework where individuals are positional also in terms of their private consumption. As such, the paper takes a broader perspective on social comparisons and tax policy than the studies referred to above. This contribution is significant for at least four reasons. First, the analysis of several different motives for charitable giving makes it possible to more clearly pin down the crucial mechanisms underlying when charitable giving should be supported and when it should not. We find that charitable giving should under certain conditions be subsidized at the margin in a second-best optimum, which runs counter to the finding of Blumkin and Sadka (2007a), who also analyze a status motive for charitable giving. In addition, the role of stigma effects of receiving charity, which to our knowledge has never been analyzed in the context of optimal taxation, turns out to be potentially very important and tends to weaken the case for subsidizing charity.

Second, if individuals try to signal status or wealth through both consumption and charitable giving - as the evidence presented above seems to suggest - the joint policy implications ought to be addressed simultaneously in the same framework. Indeed, our results show that relative concerns about private consumption directly affect the optimal policy targeted at charitable giving, which suggests that policies aimed at targeting different positional externalities may interact in important ways. Potential resource (transaction) costs associated with charitable giving play an important role in this context, since positional externalities cause a discrepancy between the private and social marginal resource costs of making charitable contributions.

\footnotetext{
${ }^{3}$ Yet, they discuss qualitatively warm-glow effects and they also explicitly analyze such effects in a workingpaper version of the paper (Blumkin and Sadka, 2007b).
} 
Third, we offer a broad perspective on tax policy implications of charitable giving by distinguishing between a case where the government can control charitable giving through a direct instrument and a case where it cannot. This distinction largely determines the policy implications of charitable giving and is also important for the optimal income tax structure. To our knowledge, a case where the government cannot directly tax or subsidize charitable giving has not been analyzed before.

Fourth, by using an optimal income tax model with information asymmetries, we are able to relate charitable giving more closely to modern literature on optimal nonlinear taxation. The results derived below give valuable information both by presenting efficiency conditions for marginal taxation of income and charitable giving, respectively, and by demonstrating that charitable giving may change both the magnitudes and signs of the optimal marginal income tax rates in cases where a direct instrument to target charitable giving is missing. In addition to realism, allowing for nonlinear taxation has the obvious advantage over more restrictive tax instruments in that the results are straightforward to interpret: tax wedges relate directly to information limitations and externalities in our model instead of to an amalgam of these motives for taxation and an arbitrary linearity restriction.

The paper is organized as follows. Section 2 presents a baseline model where consumers differ in ability, which is private information, while both income and charitable giving are fully observable to the government. As we simplify by distinguishing between only two ability types, we also assume that high-ability individuals are the sole contributors to charity and that all low-ability individuals receive an equal share of these gifts. ${ }^{4}$ Also, since charitable giving is fully observable in the base model, it follows that the government may control charitable giving through a direct (tax or subsidy) instrument, meaning in turn that the policy rules for marginal income taxation are not directly affected by charitable giving (although the levels of marginal income tax rates may well be). At the second-best optimum, we show in Section 3 that charity may either be taxed or subsidized at the margin depending on the relative strengths of the warm glow of giving and stigma from receiving charity, respectively, and on the positional externalities caused by charitable donations. We also show that positional consumption externalities directly affect this marginal tax/subsidy if charitable giving is costly.

\footnotetext{
${ }^{4}$ Thus, our model is an extension of Stiglitz' (1982) two-type model of optimal income taxation.
} 
In Section 4 we relax the assumption that the government can control charitable giving through a direct instrument. This will modify the optimal income tax structure for both ability types, since the marginal value of the positional consumption externality takes a different form here than in the baseline model. In addition, since the income tax in this case constitutes an indirect instrument through which the government may influence charitable giving, the structure of marginal income taxation of the high-ability type will change also for this reason compared with the baseline model. In general, the sign of the marginal income tax rate faced by the high-ability type is ambiguous here (even if we were to assume that positional concerns about consumption per se motivates a positive marginal income tax rate), and we give a detailed characterization of the mechanisms implicit in this tax structure. Section 5 concludes the paper, and the appendix presents the proofs and mathematical results that support the analysis of the main text.

\section{A Model with Social Comparisons and Charitable Giving}

The economy is populated by $N$ individuals, of whom $n^{1}$ are of a low-ability type $(i=1)$ and $n^{2}$ are of a high-ability type $(i=2)$. This distinction refers to productivity as measured by the before tax wage rate. The total population becomes

$$
\sum_{i=1}^{2} n^{i}=N
$$

Individuals of each type are endowed with one unit of time and supply $0 \leq l^{i} \leq 1$ units of labor. An individual of type $i$ cares about own absolute consumption, $c^{i}$, and leisure, $z^{i} \equiv 1-l^{i}$, as well as about own consumption relative to a consumption reference level, $\Delta c^{i}=c^{i}-\bar{c}$, where we follow much earlier literature on public policy and relative consumption in assuming

$$
\bar{c} \equiv \frac{1}{N} \sum_{i=1}^{2} n^{i} c^{i}
$$

i.e., the consumption reference level is given by the economy's average level of consumption. This additive specification of relative consumption is commonly used in the literature (e.g., Galí, 1994; Akerlof, 1997; Ljungqvist and Uhlig, 2000; Bowles and Park, 2005; and Aronsson and Johansson-Stenman, 2008, 2010, 2014). ${ }^{5}$

As indicated above, individuals also care about their net charitable giving, $g^{i}$, such that each individual prefers to give rather than receive charity for a given consumption level. Those

\footnotetext{
${ }^{5}$ A quotient formulation, where the individual's relative consumption is given by the ratio of his/her own consumption to the reference measure (as in, e.g., Boskin and Sheshinski, 1978; Layard, 1980; Abel, 2005; and Wendner and Goulder, 2008), would give the same qualitative results as those presented below.
} 
who give to charity will experience a warm-glow effect, whereas those who receive charity will face a stigma effect.

Those who give to charity are also concerned with their relative contribution, i.e., how much they give compared with other contributors, whereas those who receive charity analogously care about how much they receive compared with other recipients. Hence, each individual cares about $\Delta g^{i}=g^{i}-\bar{g}^{i}$, where $\bar{g}^{i}$ is the average net contribution of type $i$. Since each individual of type $i$ is identical, it follows that $\bar{g}^{i}=g^{i}$. This means that the warm-glow effect of the absolute donation is not the only motive for charitable giving; individuals also derive utility from giving more than others. By a symmetrical argument, receivers of charitable donations do not only face a direct stigma effect attached to the absolute donation, they also derive disutility by receiving more than others.

We will solely focus on the case where, in equilibrium, high-ability individuals contribute to charity and low-ability individuals receive. We also assume that there is a cost associated with charity such that the total amount received by low-ability individuals is less than the amount spent on charitable giving by high-ability individuals. For the low-ability individuals to receive $g^{2}$ dollars, the high-ability individuals will have to spend $g^{2}+\mu\left(g^{2}\right)$ dollars, where $\mu\left(g^{2}\right) \geq 0$ is the total resource cost of giving to charity. The marginal resource cost is assumed to be non-negative, $\mu_{g}\left(g^{2}\right)=\partial \mu\left(g^{2}\right) / \partial g^{2} \geq 0$. A natural interpretation is that a higher amount to be donated typically requires the household to collect more information on presumptive charities.

An important assumption is that the government is able to directly observe, and therefore also directly tax or subsidize, contributions to charity. We will give up this assumption in Section 4, where we instead assume that the government cannot tax or subsidize charity directly.

\subsection{Individual Behavior and Production}

The utility function faced by an individual of ability-type $i$ can then be written as

$$
U^{i}=v^{i}\left(c^{i}, z^{i}, g^{i}, \Delta c^{i}, \Delta g^{i}\right)=u^{i}\left(c^{i}, z^{i}, g^{i}, \bar{c}, \bar{g}^{i}\right) .
$$

The function $v^{i}(\cdot)$ defines utility as a function of absolute consumption, leisure, and net charitable giving, respectively, and of the relative consumption and relative net charitable giving, while the function $u^{i}(\cdot)$ is a convenient reduced form that helps shorten the notations. 
We assume that $v^{i}(\cdot)$ is strictly quasi-concave and increasing in all arguments. Thus, by using subscripts to denote partial derivatives, the relationships between $u^{i}(\cdot)$ and $v^{i}(\cdot)$ are summarized as $u_{c}^{i}=v_{c}^{i}+v_{\Delta c}^{i}>0, u_{z}^{i}=v_{z}^{i}>0, \quad u_{\bar{c}}^{i}=-v_{\Delta c}^{i}<0, u_{g}^{i}=v_{g}^{i}+v_{\Delta g}^{i}>0$, and $u_{\bar{g}^{i}}^{i}=-v_{\Delta g}^{i}<0$.

In our two-type setting, high-ability individuals contribute to charity and low-ability individuals receive charitable donations. Note that the charitable donation received by each low-ability individual is given by $g^{1}=-n^{2} g^{2} / n^{1}$. The individual budget constraint facing each type can then be written as

$$
\begin{aligned}
& w^{1} l^{1}+g^{2} n^{2} / n^{1}-c^{1}-T\left(w^{1} l^{1}, 0\right)=0, \\
& w^{2} l^{2}-c^{2}-g^{2}-\mu\left(g^{2}\right)-T\left(w^{2} l^{2}, g^{2}\right)=0,
\end{aligned}
$$

where $w^{i}$ denotes the hourly before-tax wage rate facing ability-type $i$, while $T\left(w^{i} l^{i}, g^{i}\right)$ is a general tax function through which the tax payment depends on both income and charitable giving. Thus, we assume that there is no tax on receiving charity, such that $T\left(w^{1} l^{1}, g^{1}\right)=T\left(w^{1} l^{1}, 0\right)$.

Individuals are assumed to be atomistic agents by treating the levels of reference consumption, $\bar{c}$, and reference giving, $\bar{g}^{i}$, as exogenous, and they choose consumption, leisure, and giving if being a high-ability type so as to maximize utility given by equation (3) subject to their respective budget constraints in equations (4). In addition to equations (4), an interior solution satisfies the following first-order conditions for work hours and giving:

$$
\begin{gathered}
M R S_{z, c}^{i} \equiv \frac{u_{z}^{i}}{u_{c}^{i}}=\frac{v_{z}^{i}}{v_{c}^{i}+v_{\Delta c}^{i}}=w^{i}\left(1-T_{w l}^{i}\right), i=1,2 \\
M R S_{g, c}^{2} \equiv \frac{u_{g}^{2}}{u_{c}^{2}}=\frac{v_{g}^{2}+v_{\Delta g}^{2}}{v_{c}^{2}+v_{\Delta c}^{2}}=1+T_{g}^{2}+\mu_{g},
\end{gathered}
$$

where $T_{w l}^{i}$ is the marginal income tax rate facing each individual of ability-type $i$ and $T_{g}^{2}$ is the marginal tax if positive or subsidy (if negative) on charitable giving faced by high-ability individuals.

Finally, there is a linear production technology with labor as the only input and where the constant marginal cost of production is normalized to one. Given competitive markets, the before-tax wage rates equal the marginal productivity of the respective type. 


\subsection{The Problem of the Government}

Following convention in the literature on optimal income taxation, the government is able to observe income, while individual ability is private information. The government is also able to fully observe and control charitable giving through direct taxes or subsidies - an assumption to be relaxed in Section 4 below. We consider a "normal case," where the government wants to redistribute from the high-ability to the low-ability type. This means that we must add a self-selection constraint that serves to prevent the high-ability type from mimicking the low-ability type in order to gain from the redistribution. By using $g^{1}=-n^{2} g^{2} / n^{1}$ and $\Delta g^{1}=g^{1}-\bar{g}^{1}=-n^{2}\left(g^{2}-\bar{g}^{2}\right) / n^{1}=-n^{2} \Delta g^{2} / n^{1}$, the utility function of the (high-ability) mimicker, denoted by a hat, ${ }^{6}$ is given by

$$
\begin{aligned}
\hat{U}^{2} & =\hat{v}^{2}\left(c^{1}, 1-\phi l^{1},-n^{2} g^{2} / n^{1}, \Delta c^{1},-n^{2} \Delta g^{2} / n^{1}\right), \\
& =\hat{u}^{2}\left(c^{1}, 1-\phi l^{1},-n^{2} g^{2} / n^{1}, \bar{c},-n^{2} \bar{g}^{2} / n^{1}\right)
\end{aligned}
$$

where $\phi \equiv w_{1} / w_{2}$ denotes the relative wage rate that converts labor (and leisure) units of the low-ability type into the corresponding units for the mimicker and $\phi l^{1}$ represents the mimicker's labor supply. The mimicker is a high-ability individual who pretends to be a lowability individual by earning the same income as the low-ability type (i.e., $w^{2} \phi l^{1}=w^{1} l^{1}$ ). Since charitable giving is fully observed by assumption, whereas ability is not, the mimicker will receive as much charity as the true low-ability individuals. Consequently, the mimicker will be subject to the same stigma and relative stigma effects. Thus, if written in terms of the function $v^{2}(\cdot)$ in equation (3), the self-selection constraint is given by

$$
v^{2}\left(c^{2}, z^{2}, g^{2}, \Delta c^{2}, \Delta g^{2}\right) \geq \hat{v}^{2}\left(c^{1}, 1-\phi l^{1},-n^{2} g^{2} / n^{1}, \Delta c^{1},-n^{2} \Delta g^{2} / n^{1}\right) .
$$

The economy's resource constraint is given by

$$
\sum_{i=1}^{2} n^{i} w^{i} l=\sum_{i=1}^{2} n^{i} c^{i}+n^{2} \mu\left(g^{2}\right)
$$

Equation (8) means that output is used for private consumption and the transaction cost associated with charitable giving. The direct transfer of charitable giving washes out of the resource constraint, as the donations are just a flow of resources from the high- to the lowability type.

The social decision problem is formulated as one of deriving a Pareto-efficient allocation by maximizing utility of the low-ability type subject to a minimum utility level for the highability type. The other constraints are given by the self-selection and resource constraints in

\footnotetext{
${ }^{6}$ Note that the mimicker and the true high-ability type share a common utility function. The hat symbol just allows us to separate them in a simple way.
} 
equations (7) and (8). The socially optimal resource allocation solves the following problem:

$$
\begin{aligned}
\underset{c^{1}, c^{2}, l^{1}, l^{2}, g^{2}}{\operatorname{Lax}} & =v^{1}\left(c^{1}, z^{1},-g^{2} n^{2} / n^{1}, \Delta c^{1},-n^{2} \Delta g^{2} / n^{1}\right) \\
& +\delta\left[v^{2}\left(c^{2}, z^{2}, g^{2}, \Delta c^{2}, \Delta g^{2}\right)-\bar{U}^{2}\right]+\gamma\left[\sum_{i=1}^{2} n^{i} w^{i} l^{i}-\sum_{i=1}^{2} n^{i} c^{i}-n^{2} \mu\left(g^{2}\right)\right], \\
& +\lambda\left[v^{2}\left(c^{2}, z^{2}, g^{2}, \Delta c^{2}, \Delta g^{2}\right)-\hat{v}^{2}\left(c^{1}, 1-\phi l^{1},-g^{2} n^{2} / n^{1}, \Delta c^{1},-n^{2} \Delta g^{2} / n^{1}\right)\right]
\end{aligned}
$$

where $\bar{U}^{2}$ specifies a fixed utility level for type 2 individuals. The Lagrange multipliers $(\delta, \gamma, \lambda)$ refer to the minimum utility, the resource, and the self-selection constraints, respectively. In contrast to individual households, the government takes the positional externalities - as arising from $\bar{c}$ and $\bar{g}^{i}-$ into account. The social first-order conditions for an interior solution can then be written as

$$
\begin{gathered}
L_{c^{1}}=v_{c}^{1}+v_{\Delta c}^{1}-\lambda\left(\hat{v}_{c}^{2}+\hat{v}_{\Delta c}^{2}\right)-\gamma n^{1}+\frac{n^{1}}{N} L_{\bar{c}}=0, \\
L_{c^{2}}=(\delta+\lambda)\left(v_{c}^{2}+v_{\Delta c}^{2}\right)-\gamma n^{2}+\frac{n^{2}}{N} L_{\bar{c}}=0, \\
L_{l^{1}}=-v_{z}^{1}+\lambda \phi \hat{v}_{z}^{2}+\gamma n^{1} w^{1}=0, \\
L_{l^{2}}=-(\delta+\lambda) v_{z}^{2}+\gamma n^{2} w^{2}=0, \\
L_{g^{2}}=(\delta+\lambda) v_{g}^{2}-v_{g}^{1} n^{2} / n^{1}+\lambda \hat{v}_{g}^{2} n^{2} / n^{1}-\gamma n^{2} \mu_{g}\left(g^{2}\right)=0 .
\end{gathered}
$$

In equations (10) and (11), $L_{\bar{c}}$ denotes the partial welfare effect of increased reference consumption, $\bar{c}$, given by

$$
L_{\bar{c}}=-v_{\Delta c}^{1}-(\delta+\lambda) v_{\Delta c}^{2}+\lambda \hat{v}_{\Delta c}^{2}
$$

\section{Optimal Taxation Results}

In this section we will derive and present the optimal marginal tax rates by comparing the social first-order conditions in equations (10)-(14) with the private first-order conditions given in equations (5) and (6). Before turning to the main task, namely to derive optimal marginal tax or subsidy rates on charity, we will present the optimal marginal income tax rates, which turn out to be analytically identical to the case without charity. For the latter task, we will for simplicity first deal with the simpler case without transaction costs.

Yet before proceeding, in order to simplify the interpretation of the optimal tax policy, let us introduce degrees of positionality with respect to consumption, $\alpha^{i}$, and charitable giving, $\beta^{i}$ : 


$$
\begin{gathered}
\alpha^{i} \equiv \frac{v_{\Delta c}^{i}}{v_{c}^{i}+v_{\Delta c}^{i}} \in(0,1), \\
\beta^{i} \equiv \frac{v_{\Delta g}^{i}}{v_{g}^{i}+v_{\Delta g}^{i}} \in(0,1) .
\end{gathered}
$$

The degree of consumption positionality, following, e.g., Johansson-Stenman et al. (2002), reflects the share of marginal utility of consumption arising from an increase in $\Delta c$. Thus, if consumption increases by one dollar, utility increases for two reasons since both absolute and relative consumption increase. The share of the utility increase that is due to increased relative consumption equals $\alpha^{i}$ for an individual of type $i$.

Similarly, the degree of charitable positionality is correspondingly defined as the share of marginal utility of charitable giving arising from an increase in $\Delta g$. If the charitable giving of the high-ability type increases by one dollar (ceteris paribus), then utility increases due to both the warm-glow effect and the (e.g., status) effect of increased relative giving. $\beta^{2}$ here reflects the share of the utility increase that is due to increased relative giving by high-ability individuals. Correspondingly, low-ability individuals who receive charity will experience a utility decrease (for a given consumption level) for two reasons, i.e., due to both an increased absolute amount of charity received and an increased amount of charity received relative to what others receive. The parameter $\beta^{1}$ reflects the share of the utility decrease attributable to the increased relative charity received.

By the assumptions made above, we have $0<\alpha^{i}<1$ and $0<\beta^{i}<1$. For further use, we also define the average degree of consumption positionality, $\bar{\alpha} \equiv\left(\alpha^{1} n^{1}+\alpha^{2} n^{2}\right) / N$, and an indicator of the difference in the degree of consumption positionality between the mimicker and the low-ability type, $\alpha^{d} \equiv\left(\hat{\alpha}^{2}-\alpha^{1}\right) \lambda \hat{u}_{c}^{2} /(\gamma N)$. Quasi-experimental research estimates $\bar{\alpha}$ to be in the interval 0.2-0.5 (see, e.g., Johansson-Stenman et al., 2002; Clark and Senik, 2005; Carlsson et al., 2007; and the overview given in Wendner and Goulder, 2008). We are not aware of any empirical estimate of the $\beta$ s .

\subsection{Optimal Marginal Income Tax Rates}

It is straightforward to show (see Appendix) that the optimal marginal income tax rates are given as (for $i=1,2)$ : 


$$
T_{w l}^{i}\left(w^{i} l^{i}, g^{i}\right)=\tau^{i}+\left[1-\tau^{i}\right] \bar{\alpha}-\left[1-\tau^{i}\right][1-\bar{\alpha}] \frac{\alpha^{d}}{1-\alpha^{d}}
$$

The variable $\tau^{i}$ is a short notation for the marginal income tax formula faced by type $i$ in the standard two-type model, in which there are no concerns about either relative consumption or charity (see the Appendix). Note that the marginal income tax rates in (18) are identical to the ones derived by Aronsson and Johansson-Stenman (2008) in a model without charitable giving. The reason equation (18) applies here as well is that the government can control charitable giving through a direct tax instrument, meaning that charitable giving will not change the policy rule for marginal income taxation. Briefly, the optimal marginal income tax thus consists of three terms, where the second term reflects the positional consumption externality and the third reflects how the government exploits differences in the degree of positionality between the mimicker and the (mimicked) low-ability type to relax the selfselection constraint. These mechanisms are discussed at length in Aronsson and JohanssonStenman (2008) and will not be further discussed here.

\subsection{Optimal Marginal Tax/Subsidy Rates for Charity without Transaction Costs}

We will now turn to the marginal tax/subsidy on charitable giving, the main task of the paper. To simplify the presentation and interpretation, we begin with the case most commonly analyzed in the literature, where there are no transaction costs of giving, i.e., where $\mu_{g}\left(g^{2}\right)=0$ for all levels of $g^{2}$. Immediately from equation (14), we obtain the following social first-order condition for charitable giving:

$$
(\delta+\lambda) v_{g}^{2} n^{1} / n^{2}=v_{g}^{1}-\lambda \hat{v}_{g}^{2}>0 .
$$

Equation (19) implies that the social marginal utility of charitable giving (the left-hand side) is equal to a "net marginal stigma cost," i.e., the social marginal stigma cost imposed on the low-ability type, $v_{g}^{1}>0$, adjusted for the social marginal benefit of imposing stigma on the mimicker, $\lambda \hat{v}_{g}^{2}>0$, which contributes to relax the self-selection constraint. It is worth noting that the social marginal benefits and costs of charitable giving are measured with the indicator of relative giving, $\Delta g^{2}$, held constant, since the externalities that relative concerns about charity give rise to are internalized in the social optimum.

In the absence of any stigma effect, in which case $v_{g}^{1}-\lambda \hat{v}_{g}^{2}=0$, an interior social optimum (if it exists) would imply $v_{g}^{2}=0$. On the other hand, if being a receiver of charity is associated 
with stigma, and if the self-selection constraint is not binding $(\lambda=0)$, first-order condition (19) means $v_{g}^{2}>0$, i.e., a lower level of charitable giving due to the marginal utility cost of stigma for the low-ability type. This stigma effect is intuitive.Yet, if the self-selection constraint is binding $(\lambda>0)$, the stigma effect on the mimicker relaxes the self-selection constraint. As a consequence, more charitable giving is optimal (i.e., $v_{g}^{2}$ is lowered by the term $\left.\lambda \hat{v}_{g}^{2}\right)$

By noting that equation (19) requires $v_{g}^{1}-\lambda \hat{v}_{g}^{2}>0$, the marginal tax/subsidy on charitable giving is characterized as follows:

Proposition 1. Without transaction costs, the optimal marginal tax/subsidy rate on charitable giving can be written as

$$
T_{g}^{2}=\frac{1}{\left(1-\beta^{2}\right)} \frac{v_{g}^{1}-\lambda \hat{v}_{g}^{2}}{\Psi}-1,
$$

where $\Psi=v_{c}^{1}+v_{\Delta c}^{1}-\lambda\left(\hat{v}_{c}^{2}+\hat{v}_{\Delta c}^{2}\right)=\frac{v_{c}^{1}}{1-\alpha^{1}}-\lambda \frac{\hat{v}_{c}^{2}}{1-\hat{\alpha}^{2}}$.

Proof: See the Appendix.

To interpret Proposition 1, we begin by discussing the special case where the self-selection constraint does not bind $(\lambda=0)$, implying that equation (20) reduces to

$$
T_{g}^{2}=\frac{1-\alpha^{1}}{1-\beta^{2}} \frac{v_{g}^{1}}{v_{c}^{1}}-1
$$

The ratio $v_{g}^{1} / v_{c}^{1}$ is a low-ability individual's marginal willingness to pay to avoid the stigma from receiving charitable donations, measured with the relative charitable benefit $\left(\Delta g^{1}\right)$ and the relative consumption ( $\left.\Delta c^{1}\right)$ held constant. As it recognizes that relative comparisons are pure waste from society's point of view, $v_{g}^{1} / v_{c}^{1}$ is interpretable as a measure of social marginal willingness to pay. If the relative concerns were absent, such that $\alpha^{1}=\beta^{2}=0$, this marginal willingness to pay would be the sole determinant of the optimal marginal tax/subsidy on charitable giving, i.e., (21) would read $T_{g}^{2}=v_{g}^{1} / v_{c}^{1}-1$. In the extreme case where the stigma effect is so large that the low-ability individual is indifferent between accepting additional charity and not, then $v_{g}^{1} / v_{c}^{1}=1$ and $T_{g}^{2}=0$, i.e., charity should be neither taxed nor subsidized 
at the margin. In the other extreme case of no stigma effect, such that $v_{g}^{1}=0$, it follows that $T_{g}^{2}=-1$, i.e., a marginal subsidy rate of 100 percent. In all cases in between, where $0<v_{g}^{1} / v_{c}^{1}<1$, it follows that $-1<T_{g}^{2}<0$, still implying that charity should be subsidized, although at a rate of less than 100 percent.

The key here is that charitable giving leads to higher utility for the donor (high-ability type) without influencing the economy's resource constraint. Moreover, we know the size of this utility increase for the donor: Since type 2 individuals give for free, and since they maximize their utility by doing so, we know that the marginal benefit of giving an additional dollar equals the marginal benefit of consuming it. Thus, if there were no stigma effect, there is an external benefit that is equally large as the donation itself, implying an optimal subsidy rate of 100 percent. Yet, the larger the stigma effect, the lower the external benefit and consequently the lower the marginal subsidy. In other words, the sole reason for the subsidy is the warmglow of giving. Without it, there would only be a social cost of charity due to the stigma effect (the transfer of consumption possibilities from high-ability to low-ability types does not give rise to a social benefit, since the government can redistribute income without costs if the self-selection constraint does not bind). We will return to the warm-glow issue later.

The multiplier $\left(1-\alpha^{1}\right) /\left(1-\beta^{2}\right)$ in equation (21) may either scale up or scale down the marginal subsidy (or may even turn it into a marginal tax) depending on whether the lowability type's degree of consumption positionality exceeds or falls short of the positional gifts externality that each high-ability individual imposes on other people of the same type through charitable contributions (measured by $\beta^{2}$ ). An increase in $\alpha^{1}$ increases the marginal subsidy for charitable giving, ceteris paribus, as it means an even greater tendency for low-ability individuals to overestimate the marginal utility of consumption and thus underestimate the marginal cost of stigma from society's point of view. ${ }^{7}$ Similarly, an increase in $\beta^{2}$ reduces the marginal subsidy (or increases the marginal tax) for charitable giving. The intuition is that $\beta^{2}$ represents the fraction of type 2 individuals' marginal utility of charitable giving that is social waste, due to that their concerns about relative contributions lead to an externality, meaning that only $1-\beta^{2}$ of an additional dollar in contribution gives rise to warm glow. The

\footnotetext{
${ }^{7}$ Note that this component has nothing to do with correction for positional consumption externalities, which is accomplished through marginal income taxation. Instead, this component arises because relative consumption concerns lead to a discrepancy between the private and social marginal utility of consumption.
} 
condition for when charity should be taxed, rather than subsidized, then follows from equation (21):

$$
T_{g}^{2}>(<) 0 \text { iff } v_{g}^{1}>(<) \frac{1-\beta^{2}}{1-\alpha^{1}} v_{c}^{1} .
$$

Let us return to the general policy rule in equation (20), which is based on the assumption that the self-selection constraint binds $(\lambda>0)$. Compared with equation (21), the most important implication is that the government has an incentive to relax the self-selection constraint by exploiting that charitable benefits lead to disutility for the mimicker due to the stigma effect. ${ }^{8}$ We can immediately see that in the extreme case of no stigma effect $\left(\lambda \hat{v}_{g}^{2}=v_{g}^{1}=0\right)$, the equally extreme result of a marginal subsidy rate of 100 percent still holds. In the opposite extreme case where there is no warm glow of giving but a negative stigma effect of receiving donations, it follows from equation (19) that $v_{g}^{1}-\lambda \hat{v}_{g}^{2}=0$, i.e., an interior solution for charitable giving may be optimal also in the absence of warm glow, since the stigma effect makes mimicking less attractive. To accomplish this, a 100 percent marginal subsidy rate is required here as well, although for a different reason. In the more interesting scenario with both warm-glow and stigma effects, the optimal second-best policy is typically to subsidize charitable giving at a marginal rate of less than 100 percent or, if the net marginal stigma cost is large enough, tax charitable giving at the margin.

Note in particular the difference in policy implications between positional giving and positional consumption. While positional consumption gives rise to an externality-correcting motive for income taxation, which shows up as a direct effect in the policy rules for marginal income taxation, there is no such direct externality-correcting charity tax in the absence of warm-glow and stigma effects. In other words, the only effect of positional gifts externalities is to weaken (strengthen) the already existing incentive to subsidize (tax) charitable giving at the margin due to warm glow and stigma.

To see the intuition behind the tax treatment of positional gifts externalities more clearly, consider the simplified case in which there is neither an absolute warm-glow effect of giving nor an absolute stigma effect from receiving charitable donations, but where high-ability individuals still care about relative giving and low-ability ones care about relative stigma. It

\footnotetext{
${ }^{8}$ Also Diamond (2006) finds that subsidized contributions may relax the self-selection constraint, although for reasons other than those discussed here. In his model, individuals may voluntarily contribute to a public good, and the utility gain of a subsidy on voluntary contributions is smaller for the mimicker than for the high-income earner.
} 
would then follow that $u_{g}^{i}=v_{\Delta g}^{i}=-u_{\bar{g}}^{i}$ and $u_{\bar{g}}^{i}=-v_{\Delta g}^{i}<0$ for $\mathrm{i}=1,2$. As a consequence, the social first-order condition for charitable giving (equation [19]) would be redundant; in fact, it would always be satisfied since $v_{g}^{1}=0, v_{g}^{2}=0$, and $\hat{v}_{g}^{2}=0$ irrespective of the level of $g^{2}$. Intuitively, if there is neither a warm-glow motive to support charitable giving, nor a stigma motive to counteract it, there are no such welfare effects on which to base public policy either. This illustrates the importance of warm-glow and stigma effects for the rationale behind taxes/subsidies on charitable giving.

\subsection{Optimal Marginal Tax/Subsidy Rates for Charity with Transaction Costs}

Let us now turn to the general and more realistic version of the model set out above with transaction costs of charitable giving. Proceeding in the same way as before, we derive the following analogue to equation (19) with transaction costs:

$$
(\delta+\lambda) v_{g}^{2}=\gamma n^{2} \mu_{g}\left(g^{2}\right)+n^{2}\left(v_{g}^{1}-\lambda \hat{v}_{g}^{2}\right) / n^{1}>0 .
$$

Equation (22) thus shows that the social marginal utility of charitable giving for the highability type, $(\delta+\lambda) v_{g}^{2}$, balances the marginal resource cost as given by $\gamma n^{2} \mu_{g}\left(g^{2}\right)$, plus the net marginal stigma cost as given by $\left(\lambda \hat{v}_{g}^{2}-v_{g}^{1}\right)$. According to equation (22), in the presence of a marginal cost of giving, the optimal level of giving should be reduced compared with a situation in which this marginal cost is nil (as in equation [19]). We can now derive:

Proposition 2. With a positive marginal transaction cost of charitable giving, the optimal marginal tax/subsidy rate for charitable giving is given by

$$
T_{g}^{2}=\frac{1}{\left(1-\beta^{2}\right)} \frac{v_{g}^{1}-\lambda \hat{v}_{g}^{2}}{\Psi}+\left[\frac{1-\bar{\alpha}}{\left(1-\alpha^{d}\right)\left(1-\beta^{2}\right)}-1\right] \mu_{g}\left(g^{2}\right)-1 .
$$

In addition to the effects of charitable giving identified in Proposition 1, the positive marginal cost of charitable giving affects the optimal marginal tax/subsidy rate in the following ways:

(i) If $\frac{1-\bar{\alpha}}{\left(1-\alpha^{d}\right)\left(1-\beta^{2}\right)}-1>0$, a higher marginal cost reduces the optimal marginal subsidy (increases the optimal marginal tax) on charitable giving, and

(ii) if $\frac{1-\bar{\alpha}}{\left(1-\alpha^{d}\right)\left(1-\beta^{2}\right)}-1<0$, a higher marginal cost increases the optimal marginal subsidy (reduces the optimal marginal tax) on charitable giving, ceteris paribus.

Proof: See the Appendix. 
The first term on the right-hand side of equation (23) is equivalent to its counterpart in equation (20) and was discussed at some length above, whereas the second term is novel and refers to the marginal cost of giving to charity. In turn, this marginal cost affects the optimal marginal subsidy/tax via two distinct effects. First, because of the resource cost of charitable giving, in order to attain a given optimal allocation, the marginal subsidy must be larger or the tax lower (in absolute terms) than without this resource cost. This is captured by the second component in square brackets.

Second, the marginal cost also affects the marginal tax (subsidy) on charitable giving via the relative concerns about both consumption and giving, as expressed by the multiplier $(1-\bar{\alpha}) /\left[\left(1-\alpha^{d}\right)\left(1-\beta^{2}\right)\right]$. As a consequence, by introducing a cost of giving, the optimal marginal subsidy/tax attached to charitable contributions will be adjusted in response to positional consumption externalities, which was not the case when this cost was nil (see Proposition 1). This is seen from the appearance of the average degree of consumption positionality, $\bar{\alpha}$, which is a measure of the marginal positional consumption externality per unit of consumption (recall that the relative consumption concerns are driven by mean-value comparisons). The average degree of positionality $\bar{\alpha}$ in the numerator of the multiplier, $(1-\bar{\alpha})$, contributes to increase the marginal subsidy (or decrease the marginal tax) on charitable giving, ceteris paribus. The intuition is that a higher marginal subsidy or lower marginal tax shifts the households' expenditure away from consumption and thus counteracts the positional consumption externality. The denominator $\left[\left(1-\alpha^{d}\right)\left(1-\beta^{2}\right)\right]$ either reinforces $\left(\alpha^{d}<0\right)$ or counteracts $\left(\alpha^{d}>0\right)$ this effect depending on whether the mimicker is more or less positional in terms of consumption than the high-ability individual. If the low-ability type is more positional than the mimicker (which means that $\alpha^{d}<0$ ), then decreased consumption contributes to relax the self-selection constraint, and if the mimicker is more positional than the low-ability type (such that $\alpha^{d}>0$ ), then increased consumption contributes to relax the self-selection constraint. Furthermore, the higher the high-ability individual's degree of positionality in charitable giving, $\beta^{2}$, the lower the marginal subsidy (the higher the marginal tax) on charitable giving, as the government realizes that relative giving is pure waste.

The components in square brackets in equation (23) can be understood in terms of a discrepancy between the private and social marginal resource cost of charitable giving, where 
the discrepancy depends on the externalities that relative concerns about consumption and donations give rise to. This discrepancy is relevant since the resource cost means that charitable contributions will reduce the total resources available for private consumption, ceteris paribus. Consider first the special case where $\alpha^{d}=0$, i.e., where the mimicker and the low-ability type are equally consumption positional, in which case an increase in $\mu_{g}(g)$ contributes to increase (decrease) the right-hand side of equation (22) if $\beta^{2}>(<) \bar{\alpha}$. This means that the larger the positional charity externality compared with the positional consumption externality, the more the marginal cost of charitable giving will contribute to reduce the marginal subsidy (or increase the marginal tax) on charitable giving. The intuition is that the private marginal resource cost underestimates its social counterpart if $\beta^{2}>\bar{\alpha}$, which the lower marginal subsidy or higher marginal tax serves to adjust for. ${ }^{9}$ An analogous interpretation in terms of increased marginal subsidies (or lower marginal taxation) of charitable giving follows when $\beta^{2}<\bar{\alpha}$.

By relaxing the assumption that $\alpha^{d}=0$, we can also see that the more consumptionpositional the mimicker is relative to the low-ability type, i.e., the larger the $\alpha^{d}$, the more $\mu_{g}(g)$ will underestimate the social marginal resource cost of charitable giving. The intuition is that the government may in this case relax the self-selection constraint by a policy-induced increase in private consumption, meaning that increased charitable giving is associated with an additional cost for that particular reason. By analogy, if the low-ability type is more consumption-positional than the mimicker, such that $\alpha^{d}<0$, increased charitable giving has the beneficial side effect of relaxing the self-selection constraint through a policy-induced decrease in private consumption, which motivates increased marginal subsidization (or decreased marginal taxation) of charitable giving at the margin.

Finally, note that if $\bar{\alpha}=\alpha^{d}=\beta^{2}=0$, i.e., if neither consumption nor charitable giving were positional goods, then the second term on the right-hand side of equation (23) would vanish. In this case, there is no longer any discrepancy between the private and social marginal resource cost of charitable giving, meaning that there is no reason for the government to

\footnotetext{
${ }^{9}$ This result is further emphasized if we assume away the relative consumption comparisons completely such that $\bar{\alpha}=0$, in which case $\beta^{2}>0$ means that the second term on the right-hand side of equation (23) is positive.
} 
adjust the marginal subsidy/tax formula in response to the marginal resource cost. Equation (23) will then coincide with equation (20).

\section{Optimal Income Taxation Without a Direct Instrument to Control Charitable Giving}

In the previous sections, we examined a case where the government is able to effectively control charitable giving through a direct tax or subsidy. Although this case is interesting and accords well with the idea that high-income consumers may have positional preferences for charitable giving, it is still not necessarily the case that charity is fully observed at the individual level by the government. One reason is, of course, that individuals may have an incentive to exaggerate their charitable giving to benefit from the subsidy, or underreport their contributions to avoid the tax described in the previous section. Another is that charitable giving is often organized by non-governmental entities with their own interests and incentives. Therefore, in this section, we analyze a scenario where the government is not able to influence charitable giving through a direct instrument, i.e., the redistribution and correction policies are solely based on income taxation. To simplify the analysis, we abstract from the resource cost of charitable giving addressed in Subsection 3.3.

\subsection{Individual Behavior}

The tax function will now be written $T^{i}=T\left(w^{i} l^{i}\right)$, as the tax payment (positive or negative) solely depends on the individual's income. The budget constraints facing low-ability and high-ability individuals then become

$$
\begin{aligned}
& w^{1} l^{1}-T\left(w^{1} l^{1}\right)+n^{2} g^{2} / n^{1}-c^{1}=0, \\
& w^{2} l^{2}-T\left(w^{2} l^{2}\right)-g^{2}-c^{2}=0,
\end{aligned}
$$

respectively. Except for this modification, the decision problem faced by the low-ability type takes exactly the same form as in the previous section, meaning that equation (5) still represents the first-order condition for work hours. For the high-ability type, the first-order condition for work hours in equation (5) also remains valid, while the first-order condition for charitable giving changes to read

$$
-u_{c}^{2}+u_{g}^{2} \leq 0 \text {. }
$$

To be able to influence charitable giving through the income tax, the government may utilize that (25) implicitly defines charitable giving as a function of the private consumption and hours of work of the high-ability type. More specifically, if (25) holds as a strict equality, we 
can solve for $g^{2}$ as a function of $c^{2}, z^{2}, \bar{c}$, and $\bar{g}^{2}$, i.e., $g^{2}=\bar{g}^{2}\left(c^{2}, z^{2}, \bar{c}, \bar{g}^{2}\right)$. By using $g^{2}=\bar{g}^{2}$, we obtain the reduced form

$$
g^{2}=g^{2}\left(c^{2}, z^{2}, \bar{c}\right) .
$$

Equation (26) is interpretable as the reaction function for $g^{2}$ perceived by the government, since the government recognizes the relationship between $g^{2}$ and $\bar{g}^{2}$. In the general case, the comparative statics of equation (26) are ambiguous. To gain some additional insights and provide intuition, we also consider a simplified version of equation (26) based on a separable utility function for the high-ability type:

$$
U^{2}=v^{2}\left(c^{2}, z^{2}, g^{2}, \Delta c^{2}, \Delta g^{2}\right)=\breve{v}\left(c^{2}, z^{2}\right)+h\left(g^{2}\right)+k\left(\Delta c^{2}\right)+q\left(\Delta g^{2}\right),
$$

where each sub-utility function is increasing in its respective argument and strictly concave, and consumption and leisure are weak (Edgeworth) complements such that $\breve{v}_{c z}^{2} \geq 0$. Then, if $g^{2}>0,(25)$ simplifies to

$$
-\left(\breve{v}_{c}\left(c^{2}, z^{2}\right)+k_{\Delta c}\left(\Delta c^{2}\right)\right)+h_{g}\left(g^{2}\right)+q_{\Delta g}\left(\Delta g^{2}\right)=0 .
$$

Totally differentiating, and using $\bar{g}^{2}=g^{2}$ gives

$$
\text { (i) } \frac{\partial g^{2}}{\partial c^{2}}>0, \quad \text { (ii) } \frac{\partial g^{2}}{\partial z^{2}} \leq 0, \quad \text { (iii) } \frac{\partial g^{2}}{\partial \bar{c}}<0 \text {. }
$$

The comparative statics in (28b) have straightforward interpretations. An increase in private consumption leads to decreased marginal utility of consumption. In turn, this leads the individual to redirect spending towards more charitable giving, ceteris paribus. On the other hand, increased use of leisure increases the marginal utility of consumption (by the assumption of complementary) and leads to increased private consumption and less charitable giving, ceteris paribus. Finally, since the individuals are positional in terms of consumption, it follows that an increase in the reference consumption increases the marginal utility of consumption, ceteris paribus, which leads to less charitable giving.

\subsection{The Government}

As in the previous sections, the government attempts to correct for positional externalities, emanating from both consumption and charitable giving, and also redistribute between the two ability types. However, in the case analyzed in this section it has no direct instrument to subsidize or tax charity By using $g^{1}=-n^{2} g^{2} / n^{1}$ and $\bar{g}^{1}=-n^{2} \bar{g}^{2} / n^{1}$ as before, the public

decision problem is to choose $l^{1}, c^{1}, l^{2}$, and $c^{2}$ to maximize utility for the low-ability type while holding utility fixed for the high-ability type subject to the self-selection constraint and the resource constraint, implying that we can write the Lagrangian as 


$$
\begin{aligned}
L & =u^{1}\left(c^{1}, z^{1},-n^{2} g^{2} / n^{1}, \bar{c},-n^{2} \bar{g}^{2} / n^{1}\right)+\delta\left[u^{2}\left(c^{2}, z^{2}, g^{2}, \bar{c}, \bar{g}^{2}\right)-\bar{U}^{2}\right] \\
& +\lambda\left[u^{2}\left(c^{2}, z^{2}, g^{2}, \bar{c}, \bar{g}^{2}\right)-\hat{u}^{2}\left(c^{1}, 1-\phi l^{1},-n^{2} g^{2} / n^{1}, \bar{c},-n^{2} \bar{g}^{2} / n^{1}\right)\right] . \\
& +\gamma \sum_{i} n^{i}\left[w^{i} l^{i}-c^{i}\right]
\end{aligned}
$$

However, $g^{2}$ is not a direct choice variable anymore and can therefore only be affected indirectly. It is here instead given by equation (26), i.e., $g^{2}=g^{2}\left(c^{2}, z^{2}, \bar{c}\right)$. We continue to assume that the mimicker does not contribute to charity, which is perhaps somewhat more questionable here, since the model no longer requires that charitable giving is observable to the government. ${ }^{10}$ For purposes of comparison, we would like to keep the model as close as possible to that of the previous section (except that the government can no longer directly control charitable giving), which means that we assume that the mimicker does not contribute to charity.

The social first-order conditions can then be written as

$$
\begin{array}{ll}
l^{1}: & -u_{z}^{1}+\lambda \phi \hat{u}_{z}^{2}+\gamma n^{1} w^{1}=0 \\
c^{1}: & u_{c}^{1}-\lambda \hat{u}_{c}^{2}-\gamma n^{1}+L_{\bar{c}} \frac{n^{1}}{N}=0 \\
l^{2}: & -(\delta+\lambda) u_{z}^{2}+\gamma n^{2} w^{2}-L_{g^{2}} \frac{\partial g^{2}}{\partial z^{2}}=0 \\
c^{2}: \quad(\delta+\lambda) u_{c}^{2}-\gamma n^{2}+L_{\bar{c}} \frac{n^{2}}{N}+L_{g^{2}} \frac{\partial g^{2}}{\partial c^{2}}=0 .
\end{array}
$$

The social first-order conditions for $l^{1}$ and $c^{1}$ given by equations (30) and (31) take the same general form as in the previous section. Yet, as we will show below, the marginal income tax rate implemented for the low-ability type will differ from the policy implemented in the previous section due to interaction effects between the positional consumption and gifts externalities. In contrast, the social first-order conditions for $l^{2}$ and $c^{2}$ in equations (32) and (33) are directly dependent on the welfare effect of charitable giving (through the partial derivative of the Lagrangian with respect to $g^{2}$ ), since changes in the hours of work and private consumption of the high-ability type affect charitable giving through the reaction function given in equation (26). This will be discussed further below.

\footnotetext{
${ }^{10}$ On the one hand, the mimicker is no longer restricted in his/her contribution behavior and may therefore want to contribute to charitable giving. On the other hand, the mimicker is also a recipient of charity, and it may seem somewhat counterintuitive to contribute to and benefit from charitable giving at the same time. In addition, recall that the mimicker has the same income as the low-ability type.
} 
To gain further insight into the implications of charitable giving for optimal income taxation, we differentiate the Lagrangian with respect to $\bar{c}$ and $g^{2}$, while using $g^{2}=\bar{g}^{2}$. This gives

$$
\begin{aligned}
& L_{\bar{c}}=u_{\bar{c}}^{1}+(\delta+\lambda) u_{\bar{c}}^{2}-\lambda \hat{u}_{\bar{c}}^{2}+L_{g} \frac{\partial g^{2}}{\partial \bar{c}} \\
& L_{g^{2}}=(\delta+\lambda) u_{g}^{2}-n^{2}\left(u_{g}^{1}-\lambda \hat{u}_{g}^{2}\right) / n^{1}+L_{\bar{g}^{2}}
\end{aligned}
$$

where

$$
L_{\bar{g}^{2}} \equiv(\delta+\lambda) u_{\bar{g}}^{2}-n^{2}\left(u_{\bar{g}}^{1}-\lambda \hat{u}_{\bar{g}}^{2}\right) / n^{1}
$$

Recall from the previous section that $u_{\bar{c}}^{i}=-\alpha^{i} u_{c}^{i}, \hat{u}_{\bar{c}}^{2}=-\hat{\alpha}^{2} \hat{u}_{c}^{2}$, and $u_{\bar{g}}^{i}=-\beta^{i} u_{g}^{i}$ for $i=1,2$. By using equations (31), (33), (34a), (34b), and (34c), we can then derive

$$
\begin{aligned}
L_{g^{2}} & =(\delta+\lambda) u_{g}^{2}\left(1-\beta^{2}\right)-n^{2}\left(u_{g}^{1}\left(1-\beta^{1}\right)-\lambda \hat{u}_{g}^{2}\left(1-\hat{\beta}^{2}\right)\right) / n^{1} \\
& =(\delta+\lambda) v_{g}^{2}-n^{2}\left(v_{g}^{1}-\lambda \hat{v}_{g}^{2}\right) / n^{1} \\
L_{\bar{c}} & =-\gamma N \frac{\bar{\alpha}-\alpha^{d}}{1-\bar{\alpha}}+\frac{1}{1-\bar{\alpha}}\left((\delta+\lambda) v_{g}^{2}-n^{2}\left(v_{g}^{1}-\lambda \hat{v}_{g}^{2}\right) / n^{1}\right)\left(\frac{\partial g^{2}}{\partial \bar{c}}+\alpha^{2} \frac{\partial g^{2}}{\partial c^{2}}\right) .
\end{aligned}
$$

Note that the right-hand side of equation (35a) can be either positive or negative. It contains the components of the social first-order condition for $g^{2}$ derived in equation (19) in Section 2, although the three terms do not necessarily sum to zero here. The first term on the right-hand side of equation (35b) is the direct partial welfare effect of increased reference consumption, which depends on the average degree of consumption positionality, $\bar{\alpha}$, and the difference in the degree of consumption positionality between the mimicker and the low-ability type, $\alpha^{d}$ (as defined in the previous section). We can see that the larger the $\bar{\alpha}$, the greater the welfare cost of increased reference consumption, ceteris paribus. This effect is, in turn, either reinforced $\left(\alpha^{d}<0\right)$ or counteracted $\left(\alpha^{d}>0\right)$ by an incentive to relax the self-selection constraint by exploiting that the mimicker and the low-ability type typically differ in terms of degree of consumption positionality.

The second term on the right-hand side of equation (35b) is an indirect welfare effect of increased reference consumption and arises because the two externalities interact through the reaction function for $g^{2}$ in equation (26). As such, this component depends on the social cost benefit rule for $g^{2}$ and would, of course, vanish in a setting where the government directly controls charitable giving, in which case the social first-order condition for $g^{2}$ would read $(\delta+\lambda) v_{g}^{2}-n^{2}\left(v_{g}^{1}-\lambda \hat{v}_{g}^{2}\right) / n^{1}=0$. The multiplier $\partial g^{2} / \partial \bar{c}+\alpha^{2} \partial g^{2} / \partial c^{2}$ reflects two different 
channels through which the two positional externalities interact. These channels are (i) a direct effect of $\bar{c}$ on $g^{2}$ and, therefore, on $\bar{g}^{2}$, and (ii) a feedback effect because $\bar{c}$ affects $c^{2}$ through equation (33). The latter effect depends on the high-ability type's degree of consumption positionality: the higher the degree, the stronger the feedback effect. According to the comparative statics based on the simplified utility function in equation (27), $\partial g^{2} / \partial \bar{c}<0$ and $\partial g^{2} / \partial c^{2}>0$. Thus, the lower the high-ability type's degree of consumption positionality, the more likely it is that $\partial g^{2} / \partial \bar{c}+\alpha^{2} \partial g^{2} / \partial c^{2}$ is a negative number.

We are now ready to derive the marginal income tax rates, which is accomplished by combining the social first-order conditions in equations (30)-(33) with the private first-order condition for labor supply in equation (5). The marginal income tax policy is summarized in Proposition 3.

Proposition 3. If the government lacks a direct instrument to control the charitable giving, the optimal marginal income tax rates can be characterized as

$$
\begin{aligned}
& T_{w l}^{1}=\frac{\lambda^{*}}{n^{1} w^{1}}\left(M R S_{z, c}^{1}-\phi M \hat{R} S_{z, c}^{2}\right)-\frac{L_{\bar{c}}}{w^{1} \gamma N} M R S_{z, c}^{1}, \\
& T_{w l}^{2}=-M R S_{z, c}^{2} \frac{L_{\bar{c}}}{w^{2} \gamma N}+\frac{L_{g}}{\gamma w^{2} n^{2}}\left(\frac{\partial g^{2}}{\partial z^{2}}-M R S_{z, c}^{i} \frac{\partial g^{2}}{\partial c^{2}}\right),
\end{aligned}
$$

where $\lambda^{*}=\lambda \hat{u}_{c}^{2} / \gamma, M R S_{z, c}^{i}=\frac{u_{z}^{i}}{u_{c}^{i}}$ for $i=1,2$, and $M \hat{R} S_{z, c}^{2}=\frac{\hat{u}_{z}^{2}}{\hat{u}_{c}^{2}}$.

Proof: See the Appendix.

The low-ability type's marginal income tax rate given in equation (36a) takes the same general form as in Aronsson and Johansson-Stenman (2008), with the modification that the welfare effect of increased reference consumption is now given by equation (35b). As a consequence, the sign of the second term on the right-hand side no longer depends only on the average degree of positionality and the difference in the degree of positionality between the mimicker and the low-ability type (as above). It also depends on whether an increase in $g$ leads to higher or lower social welfare. An analogous effect appears as the first term on the right-hand side in the marginal income tax formula for the high-ability type given in equation (36b). 
To provide intuition behind the tax policy implications of consumption positionality, and in particular the implications of the second term on the right-hand side of equation (35b), we add the (reasonable) assumption that $\bar{\alpha}>\alpha^{d}$, in which case the first term on the right-hand side of equation (35b) is negative, and then use the simplified utility function given in equation (27) and associated comparative statics in (28b). It follows that the partial welfare effect of increased reference consumption, as specified in equation (35b), is negative if

$$
\left((\delta+\lambda) v_{g}^{2}-n^{2}\left(v_{g}^{1}-\lambda \hat{v}_{g}^{2}\right) / n^{1}\right)\left[\frac{\partial g^{2}}{\partial \bar{c}}+\alpha^{2} \frac{\partial g^{2}}{\partial c^{2}}\right]<0,
$$

where $\partial g^{2} / \partial \bar{c}<0$ and $\partial g^{2} / \partial c^{2}>0$ by (28b). Since the functional form assumption for the utility function implies $\left|\partial g^{2} / \partial c^{2}\right|>\left|\partial g^{2} / \partial \bar{c}\right|$, the sign of the term within the square bracket depends on the high-ability type's degree of consumption positionality. If this degree is sufficiently high, such that $\partial g^{2} / \partial \bar{c}+\alpha^{2} \partial g^{2} / \partial c^{2}>0$, the negative sign of (37) requires that charity is over-provided relative to the second-best optimal provision rule in Section 2, i.e., $(\delta+\lambda) v_{g}^{2}<n^{2}\left(v_{g}^{1}-\lambda \hat{v}_{g}^{2}\right) / n^{1}$. This exemplifies an incentive to increase the marginal income tax rates for both ability types that in turn leads to a smaller positional consumption externality as well as a simultaneous decrease in the level of charitable giving (both of which are desirable).

On the other hand, if the high-ability type's degree of consumption positionality is low enough such that $\partial g^{2} / \partial \bar{c}+\alpha^{2} \partial g^{2} / \partial c^{2}<0$, and if we continue to assume that charitable giving is over-provided in equilibrium relative to the second-best optimal policy rule, (37) will be replaced with

$$
\left((\delta+\lambda) v_{g}^{2}-n^{2}\left(v_{g}^{1}-\lambda \hat{v}_{g}^{2}\right) / n^{1}\right)\left(\frac{\partial g^{2}}{\partial \bar{c}}+\alpha^{2} \frac{\partial g^{2}}{\partial c^{2}}\right)>0 .
$$

In this case, the two terms on the right-hand side of equation (35b) differ in sign (under the assumption that $\bar{\alpha}>\alpha^{d}$ ), meaning that the marginal tax policy implication of the positional consumption externality is ambiguous (since a decrease in this externality would lead to an increase in the already over-provided charitable giving). 
Finally, note that policy implications opposite to those just discussed would follow if charitable giving were under-provided in equilibrium relative to the second-best optimal policy rule, i.e., if $(\delta+\lambda) v_{g}^{2}>n^{2}\left(v_{g}^{1}-\lambda \hat{v}_{g}^{2}\right) / n^{1}$.

The second term on the right-hand side of equation (36b) is also novel and arises because the high-ability type's labor supply and consumption choices directly affect the charitable giving and, therefore, the tax policy incentives. Note first that this effect has nothing to do with consumption positionality (i.e., it would be present also in a model without consumption positionality where $L_{\bar{c}}=0$ ). To provide intuition, consider once again the simplified utility function with comparative statics in $(28 \mathrm{~b})$, in which case

$$
\frac{\partial g^{2}}{\partial z^{2}}-M R S_{z, c}^{2} \frac{\partial g^{2}}{\partial c^{2}}<0
$$

With (39) at our disposal, it follows that the second term on the right-hand side of equation (36b) constitutes an incentive to tax high-ability labor at the margin if $(\delta+\lambda) v_{g}^{2}<n^{2}\left(v_{g}^{1}-\lambda \hat{v}_{g}^{2}\right) / n^{1}$. In this scenario, the high-ability type over-provides charitable donations relative to the policy rule ideally preferred by the government in equation (19). Therefore, by reducing high-ability type's labor supply and disposable income, less will be spent on charitable giving. If instead $(\delta+\lambda) v_{g}^{2}>n^{2}\left(v_{g}^{1}-\lambda \hat{v}_{g}^{2}\right) / n^{1}$, meaning that the highability type under-provides charitable donations in equilibrium, there is an analogous incentive to reduce the marginal income tax rate facing the high-ability type. The intuition is that lower marginal income taxation leads to increased charitable giving, which is desirable as long as giving falls below the level implied by equation (19).

\section{Conclusions}

In this paper, we have analyzed optimal tax policy responses to private charity from richer to poorer people based on a two-type model of optimal nonlinear income taxation. We consider a rich behavioral model where receiving charity is associated with a stigma effect and where potential givers are motivated not only by warm glow but also status concerns associated with giving more than others. Furthermore, since status concerns in terms of private consumption may affect the incentives of giving to charity, and thus also the optimal policy directed at charitable giving, our model also assumes that people care about their relative consumption compared with others. 
An important take-home message of the paper is that the warm glow of giving and stigma from receiving charity play crucial roles for whether charitable giving should be subsidized or taxed at the margin. In a first-best resource allocation, where the self-selection constraint does not bind, and in the absence of any transaction cost of charitable contributions, a necessary condition for subsidizing charity at the margin is that givers experience a warm glow. Diamond (2006) argues against using such warm-glow welfare effects as a basis for taxation. If we would follow Diamond and disregard warm-glow welfare effects, the case for public charity support would thus be considerably weakened. Yet, in a second-best resource allocation with a binding self-selection constraint, it may be optimal to subsidize charitable giving at the margin also in the absence of any warm glow, since the stigma effect of receiving charity contributes to relax the self-selection constraint.

When introducing transaction costs of charitable giving in the model, we find that the marginal transaction cost contributes to marginal subsidization (taxation) of charitable giving if the positional consumption externality exceeds (falls short of) the positional gifts externality. The intuition is that these externalities lead to a discrepancy between the public and private marginal resource cost of charitable giving. Overall, and based on our analysis, there are cases both for taxing and subsidizing charitable giving. Finally, we characterize how the optimal marginal income tax policy responds to charitable giving in a case where the government lacks a direct instrument for taxing or subsidizing charity, and derive conditions under which this results in higher or lower marginal income taxes implemented for both ability types.

We note the following limitations in our analysis. First, we do not consider the case in which households feel social pressure to donate, as demonstrated in DellaVigna et al. (2012). ${ }^{11}$ Second, our theoretical analysis emphasizes the effects of relative comparisons of charitable giving, as well as the interactions between concerns about relative consumption and relative charitable giving. However, although the evidence discussed in the introduction points to a status motive for charitable contributions, so far there exists no empirical evidence regarding the degree of positionality with respect to charitable giving $\left({ }^{2}\right)$. These limitations define significant future research questions. Notwithstanding these limitations, we hope this study clarifies the theoretical impact of the interactions between relative comparisons of charitable

\footnotetext{
${ }^{11}$ Based on a field-experimental design of door-to-door fundraising, DellaVigna et al. (2012) conclude that a common reason for donating is social pressure and that it may even be the case that such charity campaigns on average reduce the net utility of potential givers.
} 
giving and consumption on (second-best) optimal nonlinear taxation of charitable giving and income, and that it can contribute to future discussions on tax reform when positional preferences are accounted for.

\section{Appendix}

\section{Derivation of Equation (18)}

Consider first the low-ability type. From equation (12) we can derive

$$
M R S_{z, c}^{1}\left(v_{c}^{1}+v_{\Delta c}^{1}\right)=\lambda \phi \hat{v}_{z}^{2}+\gamma n^{1} w^{1} .
$$

Equation (10) implies

$$
v_{c}^{1}+v_{\Delta c}^{1}=\gamma n^{1}+\lambda \hat{v}_{c}^{2}+\lambda \hat{v}_{\Delta c}^{2}-\frac{n^{1}}{N} L_{\bar{c}} .
$$

Combining equations (A1) and (A2) yields

$$
\begin{aligned}
\operatorname{MRS}_{z, c}^{1}\left(\lambda \hat{v}_{c}^{2}+\lambda \hat{v}_{\Delta c}^{2}-\frac{n^{1}}{N} L_{\bar{c}}\right) & =\lambda \phi \hat{v}_{z}^{2}+\gamma n^{1}\left(w^{1}-M R S_{z, c}^{1}\right), \\
& =\lambda \phi \hat{v}_{z}^{2}+\gamma n^{1} T_{w l}^{2} w^{1}
\end{aligned}
$$

where in the last step we have used the private optimum condition for labor supply, i.e., equation (5). From equation (1) follows that for each type (including the mimicker)

$$
v_{\Delta c}^{i}=\alpha^{i}\left(v_{c}^{i}+v_{\Delta c}^{i}\right),
$$

which substituted into equation (15) implies

$$
L_{\bar{c}}=-\alpha^{1}\left(v_{c}^{1}+v_{\Delta c}^{1}\right)-(\delta+\lambda) \alpha^{2}\left(v_{c}^{2}+v_{\Delta c}^{2}\right)+\lambda \hat{\alpha}^{2}\left(\hat{v}_{c}^{2}+\hat{v}_{\Delta c}^{2}\right) .
$$

Note also that Equation (11) can be rearranged such that

$$
(\delta+\lambda)\left(v_{c}^{2}+v_{\Delta c}^{2}\right)=\gamma n^{2}-\frac{n^{2}}{N} L_{\bar{c}} .
$$

Substituting equations (A2) and (A6) into equation (A5) yields

$$
\begin{aligned}
L_{\bar{c}} & =-\alpha^{1}\left(\gamma n^{1}+\lambda\left(\hat{v}_{c}^{2}+\hat{v}_{\Delta c}^{2}\right)-\frac{n^{1}}{N} L_{\bar{c}}\right)-\alpha^{2}\left(\gamma n^{2}-\frac{n^{2}}{N} L_{\bar{c}}\right)+\lambda \hat{\alpha}^{2}\left(\hat{v}_{c}^{2}+\hat{v}_{\Delta c}^{2}\right) \\
& =\bar{\alpha} L_{\bar{c}}-\bar{\alpha} \gamma N+\lambda\left(\hat{v}_{c}^{2}+\hat{v}_{\Delta c}^{2}\right)\left(\hat{\alpha}^{2}-\alpha^{1}\right) \\
& =-\gamma N \frac{\bar{\alpha}}{1-\bar{\alpha}}+\lambda\left(\hat{v}_{c}^{2}+\hat{v}_{\Delta c}^{2}\right) \frac{\hat{\alpha}^{2}-\alpha^{1}}{1-\bar{\alpha}}
\end{aligned}
$$

where we have used equation (16). Solving for the optimal marginal income tax rate in equation (3) and substituting equation (A7) then imply 


$$
\begin{aligned}
T_{w l}^{1} & =\frac{M R S_{z, c}^{1}}{\gamma n^{1} w^{1}}\left(\lambda \hat{v}_{c}^{2}+\lambda \hat{v}_{\Delta c}^{2}-\frac{n^{1}}{N} L_{\bar{c}}\right)-\frac{\lambda \phi \hat{v}_{z}^{2}}{\gamma n^{1} w^{1}} \\
& =\frac{M R S_{z, c}^{1}}{\gamma n^{1} w^{1}}\left(\lambda \hat{v}_{c}^{2}+\lambda \hat{v}_{\Delta c}^{2}-\frac{n^{1}}{N}\left(-\gamma N \frac{\bar{\alpha}}{1-\bar{\alpha}}+\lambda\left(\hat{v}_{c}^{2}+\hat{v}_{\Delta c}^{2}\right) \frac{\hat{\alpha}^{2}-\alpha^{1}}{1-\bar{\alpha}}\right)\right)-\frac{\lambda \phi \hat{v}_{z}^{2}}{\gamma n^{1} w^{1}}, \\
& =\frac{\lambda \hat{u}_{c}^{2}}{\gamma n^{1} w^{1}}\left(M R S_{z, c}^{1}-\phi M \hat{R} S_{z, c}^{1}\right)+\frac{M R S_{z, c}^{1}}{w^{1}}\left(\frac{\bar{\alpha}}{1-\bar{\alpha}}-\frac{\lambda\left(\hat{v}_{c}^{2}+\hat{v}_{\Delta c}^{2}\right)}{\gamma N} \frac{\hat{\alpha}^{2}-\alpha^{1}}{1-\bar{\alpha}}\right) \\
& =\tau^{1}+\frac{M R S_{z, c}^{1}}{w^{1}}\left(\frac{\bar{\alpha}}{1-\bar{\alpha}}-\frac{\alpha^{d}}{1-\bar{\alpha}}\right)
\end{aligned}
$$

where

$$
\tau^{1}=\frac{\lambda \hat{u}_{c}^{2}}{\gamma n^{1} w^{1}}\left(M R S_{z, c}^{1}-\phi M \hat{R} S_{z, c}^{1}\right)
$$

is the policy rule for marginal income taxation for type 1 individuals in the original Stiglitz (1982) model, in which there are no relative consumption concerns. Let us finally again use the private optimum condition, equation (5), in equation (A8) in order to obtain

$$
T_{w l}^{1}=\tau^{1}+\left(1-T_{w l}^{1}\right)\left(\frac{\bar{\alpha}}{1-\bar{\alpha}}-\frac{\alpha^{d}}{1-\bar{\alpha}}\right)
$$

Solving for $T_{w l}^{1}$ and re-arranging gives equation (18) for type 1 individuals. Equation (18) for type 2 individuals is derived similarly, in which $\tau^{2}=0$.

\section{Proof of Propositions 1 and 2}

Consider first the proof of Proposition 2. From the individual optimum condition for charity, equation (6), follows that

$$
T_{g}^{2}=\frac{v_{g}^{2}+v_{\Delta g}^{2}}{v_{c}^{2}+v_{\Delta c}^{2}}-1-\mu_{g}\left(g^{2}\right)=\frac{v_{g}^{2} \frac{v_{g}^{2}+v_{\Delta g}^{2}}{v_{g}^{2}}}{v_{c}^{2}+v_{\Delta c}^{2}}-1-\mu_{g}\left(g^{2}\right)=\frac{1}{1-\beta^{2}} \frac{v_{g}^{2}}{v_{c}^{2}+v_{\Delta c}^{2}}-1-\mu_{g}\left(g^{2}\right)(\mathrm{A} 1
$$

where we used equation (17) in the last step. By using the social first-order condition for charitable giving in equation (14), we can then derive

$$
v_{g}^{2}=\frac{v_{g}^{1}+\gamma n^{1} \mu_{g}\left(g^{2}\right)-\lambda \hat{v}_{g}^{2}}{\delta+\lambda} \frac{n^{2}}{n^{1}}
$$

The social first-order condition for consumption among type 2 individuals, equation (11), implies 


$$
\begin{aligned}
v_{c}^{2}+v_{\Delta c}^{2} & =\frac{\gamma n^{2}-\frac{n^{2}}{N} L_{\bar{c}}}{\delta+\lambda}=\frac{\gamma n^{2}+\frac{n^{2}}{N}\left(\gamma N \frac{\bar{\alpha}}{1-\bar{\alpha}}-\lambda\left(\hat{v}_{c}^{2}+\hat{v}_{\Delta c}^{2}\right) \frac{\hat{\alpha}^{2}-\alpha^{1}}{1-\bar{\alpha}}\right)}{\delta+\lambda} . \\
& =\frac{1}{1-\bar{\alpha}} \frac{\gamma n^{2}}{\delta+\lambda}\left(1-\alpha^{d}\right)
\end{aligned}
$$

Substituting equations (A11) and (A12) into equation (A10) then gives

$$
\begin{aligned}
T_{g}^{2} & =\frac{1-\bar{\alpha}}{1-\alpha^{d}} \frac{v_{g}^{1}+\gamma n^{1} \mu_{g}\left(g^{2}\right)-\lambda \hat{v}_{g}^{2}}{\gamma n^{1}\left(1-\beta^{2}\right)}-\mu_{g}\left(g^{2}\right)-1 \\
& =\frac{1-\bar{\alpha}}{1-\alpha^{d}} \frac{v_{g}^{1}-\lambda \hat{v}_{g}^{2}}{\gamma n^{1}\left(1-\beta^{2}\right)}+\frac{1-\bar{\alpha}}{1-\alpha^{d}} \frac{\mu_{g}\left(g^{2}\right)}{1-\beta^{2}}-\mu_{g}\left(g^{2}\right)-1 \\
& =\frac{1-\bar{\alpha}}{1-\alpha^{d}} \frac{v_{g}^{1}-\lambda \hat{v}_{g}^{2}}{\gamma n^{1}\left(1-\beta^{2}\right)}+\mu_{g}\left(g^{2}\right)\left(\frac{1-\bar{\alpha}}{1-\alpha^{d}} \frac{1}{1-\beta^{2}}-\frac{1-\alpha^{d}}{1-\alpha^{d}} \frac{1-\beta^{2}}{1-\beta^{2}}\right)-1 . \\
& =\frac{1-\bar{\alpha}}{1-\alpha^{d}} \frac{v_{g}^{1}-\lambda \hat{v}_{g}^{2}}{\gamma n^{1}\left(1-\beta^{2}\right)}-\frac{\bar{\alpha}-\alpha^{d}-\beta^{2}\left(1-\alpha^{d}\right)}{\left(1-\alpha^{d}\right)\left(1-\beta^{2}\right)} \mu_{g}\left(g^{2}\right)-1 \\
& =\frac{1-\bar{\alpha}}{1-\alpha^{d}} \frac{v_{g}^{1}-\lambda \hat{v}_{g}^{2}}{\gamma n^{1}\left(1-\beta^{2}\right)}+\left[\frac{1-\bar{\alpha}}{\left(1-\alpha^{d}\right)\left(1-\beta^{2}\right)}-1\right] \mu_{g}\left(g^{2}\right)-1
\end{aligned}
$$

Let us finally eliminate $\gamma n^{1}$. Solving equation (10) for $\gamma n^{1}$ gives

$$
\begin{aligned}
\gamma n^{1} & =v_{c}^{1}+v_{\Delta c}^{1}-\lambda \hat{v}_{c}^{2}-\lambda \hat{v}_{\Delta c}^{2}+\frac{n^{1}}{N} L_{\bar{c}} \\
& =v_{c}^{1}+v_{\Delta c}^{1}-\lambda \hat{v}_{c}^{2}-\lambda \hat{v}_{\Delta c}^{2}-\gamma n^{1} \frac{\bar{\alpha}-\alpha^{d}}{1-\bar{\alpha}}
\end{aligned}
$$

Now, using $v_{c}^{1}+v_{\Delta c}^{1}=v_{c}^{1} /\left(1-\alpha^{1}\right)$ and $\hat{v}_{c}^{2}+\hat{v}_{\Delta c}^{2}=\hat{v}_{c}^{2} /\left(1-\hat{\alpha}^{2}\right)$, and then collecting the $\gamma n^{1}-$ terms, equation (A14) can be written as

$$
\gamma n^{1}=\frac{1-\bar{\alpha}}{1-\alpha^{d}}\left[v_{c}^{1} /\left(1-\alpha^{1}\right)-\lambda \hat{v}_{c}^{2} /\left(1-\hat{\alpha}^{2}\right)\right] .
$$

Substituting equation (A15) into equation (A13) gives equation (23) in Proposition 2. Equation (20) in Proposition 1 follows as the special case where $\mu_{g}\left(g^{2}\right)=0$.

\section{Proof of Proposition 3}

Consider first the marginal income tax formula for the low-ability type. Combining equations (30) and (31) gives

$$
\frac{u_{z}^{2}}{u_{c}^{2}}\left[\lambda \hat{u}_{c}^{2}+\gamma n^{1}-L_{\bar{c}} \frac{n^{1}}{N}\right]=\lambda \phi \hat{u}_{z}^{2}+\gamma n^{1} w^{1}
$$

By using $w^{1}-u_{z}^{1} / u_{c}^{1}=w^{1} T_{w l}^{1}$ in equation (A16) and then solving for $T_{w l}^{1}$, we can derive 


$$
T_{w l}^{1}=\frac{\lambda \hat{u}_{c}^{2}}{\gamma n^{1} w^{1}}\left(\frac{u_{z}^{1}}{u_{c}^{1}}-\phi \frac{\hat{u}_{z}^{2}}{\hat{u}_{c}^{2}}\right)-\frac{u_{z}^{1}}{u_{c}^{1}} \frac{L_{\bar{c}}}{w^{1} \gamma N}
$$

which is equation (36a).

Turning to the marginal income tax formula for the high-ability type, we can similarly combine equations (32) and (33) to derive

$$
\frac{u_{z}^{2}}{u_{c}^{2}}\left[\gamma n^{2}-L_{\bar{c}} \frac{n^{2}}{N}-L_{g^{2}} \frac{\partial g^{2}}{\partial c^{2}}\right]=\gamma n^{2} w^{2}-L_{g^{2}} \frac{\partial g^{2}}{\partial z^{2}} .
$$

Using $w^{2}-u_{z}^{2} / u_{c}^{2}=w^{2} T_{w l}^{2}$ in equation (A18) and solving for $T_{w l}^{2}$ gives

$$
T_{w l}^{2}=-\frac{u_{z}^{2}}{u_{c}^{2}} \frac{L_{\bar{c}}}{w^{2} \gamma N}+\frac{L_{g}}{\gamma w^{2} n^{2}}\left(\frac{\partial g^{2}}{\partial z^{2}}-\frac{u_{z}^{2}}{u_{c}^{2}} \frac{\partial g^{2}}{\partial c^{2}}\right),
$$

which is equation (36b).

To derive equation (35b), we use $u_{\bar{c}}^{i}=-\alpha^{i} u_{c}^{i}$ for $i=1,2$ and $\hat{u}_{\bar{c}}^{2}=-\hat{\alpha}^{2} \hat{u}_{c}^{2}$. Substituting into equation $(34 \mathrm{a})$ gives

$$
L_{\bar{c}}=-\alpha^{1} u_{c}^{1}-(\delta+\lambda) \alpha^{2} u_{c}^{2}+\lambda \hat{\alpha}^{2} \hat{u}_{c}^{2}+L_{g} \frac{\partial g^{2}}{\partial \bar{c}} .
$$

Solving equation (31) for $u_{c}^{1}$ and equation (33) for $(\delta+\lambda) u_{c}^{2}$, respectively, such that

$$
\begin{aligned}
& u_{c}^{1}=\lambda \hat{u}_{c}^{2}+\gamma n^{1}-L_{\bar{c}} \frac{n^{1}}{N} \\
& (\delta+\lambda) u_{c}^{2}=\gamma n^{2}-L_{\bar{c}} \frac{n^{2}}{N}-L_{g^{2}} \frac{\partial g^{2}}{\partial c^{2}},
\end{aligned}
$$

and substituting into equation (A20) implies

$$
\begin{aligned}
L_{\bar{c}} & =-\alpha^{1}\left(\lambda \hat{u}_{c}^{2}+\gamma n^{1}-L_{\bar{c}} \frac{n^{1}}{N}\right)-\alpha^{2}\left(\gamma n^{2}-L_{\bar{c}} \frac{n^{2}}{N}-L_{g^{2}} \frac{\partial g^{2}}{\partial c^{2}}\right) . \\
& +\lambda \hat{\alpha}^{2} \hat{u}_{c}^{2}+L_{g} \frac{\partial g^{2}}{\partial \bar{c}}
\end{aligned}
$$

Collecting $L_{\bar{c}}$-terms and rearranging gives

$$
\begin{aligned}
L_{\bar{c}}\left(1-\frac{n^{1} \alpha^{1}+n^{2} \alpha^{2}}{N}\right) & =-\gamma\left(n^{1} \alpha^{1}+n^{2} \alpha^{2}\right)+\lambda \hat{u}_{c}^{2}\left(\hat{\alpha}^{2}-\alpha^{1}\right) \\
& +L_{g^{2}}\left(\frac{\partial g^{2}}{\partial \bar{c}}+\alpha^{2} \frac{\partial g^{2}}{\partial c^{2}}\right)
\end{aligned} .
$$


Finally, by using the expression for $L_{g^{2}}$ in equation (35a) and substituting into equation (A22), we obtain equation (35b).

\section{References}

Abel, A.B., (2005) Optimal Taxation When Consumers Have Endogenous Benchmark Levels of Consumption. Review of Economic Studies 72, 1-19.

Akerlof, G.A., (1997) Social Distance and Social Decisions. Econometrica 65, 1005-1028.

Andreoni, J., (1989) Giving with Impure Altruism: Applications to Charity and Ricardian Equivalence. Journal of Political Economy 97, 1447-1458.

Andreoni, J., (1990) Impure Altruism and Donations to Public Goods: A Theory of WarmGlow Giving. Economic Journal 100, 464-77.

Aronsson, T., O. Johansson-Stenman, (2008) When the Joneses' Consumption Hurts: Optimal Public Good Provision and Nonlinear Income Taxation. Journal of Public Economics 92, 986-997.

Aronsson, T., O, Johansson-Stenman, (2010) Positional Concerns in an OLG Model: Optimal Labor and Capital Income Taxation. International Economic Review 51, 1071-1095.

Aronsson, T., O, Johansson-Stenman, (2014) When Samuelson met Veblen Abroad: National and Global Public Good Provision When Social Comparisons Matter. Economica 81, 224-243.

Atkinson, A.B., (1976) The Income Tax Treatment of Charitable Contributions. In: Grieson, R. (Ed.), Public and Urban Economics: Essays in the Honor of William S. Vickrey. D.C. Heath, New York.

Auten, G., H. Sieg, C.T. Clotfelter, (2002) Charitable Giving, Income and Taxes: An Analysis of Panel Data. American Economic Review 92, 371-382.

Besley, T., S. Coate, (1992) Understanding welfare stigma: Taxpayer resentment and statistical discrimination, Journal of Public Economics 48, 165-184.

Blanchflower, D.G., A.J. Oswald, (2004) Well-Being Over Time in Britain and the USA. Journal of Public Economics 88, 1359-1386.

Blumkin, T., E. Sadka, (2007a) A case for taxing charitable donations. Journal of Public Economics 91 (7-8), 1555-1564.

Blumkin, T., E. Sadka, (2007b) On the Desirability of Taxing Charitable Contributions. CesIfo Discussion Paper, 2007. 
Boskin, M.J., E. Sheshinski, (1978) Individual Welfare Depends Upon Relative Income. Quarterly Journal of Economics 92, 589-601.

Bowles, S., Y. Park, (2005) Emulation, Inequality, and Work Hours: Was Thorsten Veblen Right? Economic Journal 115, F397-F412.

Carlsson, F., O. Johansson-Stenman, P. Martinsson, (2007) Do You Enjoy Having More Than Others? Survey Evidence of Positional Goods. Economica 74, 586-598.

Cartwright, E., A. Patel, (2013) How Category Reporting can Improve Fundraising. Journal of Economic Behavior and Organization 87, 73-90.

Clark, A.E., A.J. Oswald, (1994) Unhappiness and Unemployment, Economic Journal 104, $648-659$.

Clark, A., C. Senik, (2010) Who Compares to Whom? The Anatomy of Income Comparisons in Europe. Economic Journal 120, 573-594.

Clotfelter, C.T. (Ed.), (1992) Who Benefits from the Nonprofit Sector. The University of Chicago Press, Chicago.

Clotfelter, C.T., (2014) Charitable Giving and Tax Policy in the U.S. In: Fack, G., C. Landais (Eds.), Charitable Giving and Tax Policy: A Historical and Comparative Perspective. Oxford, Oxford University Press.

DellaVigna, S., J. List, U. Malmendier, (2012) Testing for Altruism and Social Pressure in Charitable Giving. Quarterly Journal of Economics 127, 1-56.

Diamond, P., (2006) Optimal Tax Treatment of Private Contributions for Public Goods with and Without Warm-Glow Preferences. Journal of Public Economics 90, 897-919.

Dupor, B., W.F. Liu, (2003) Jealousy and Overconsumption. American Economic Review 93, $423-428$.

Easterlin, R.A., (2001) Income and Happiness: Towards a Unified Theory. Economic Journal $111,465-484$.

Eckerstorfer, P. and Wendner, R. (2013) Asymmetric and Non-atmospheric Consumption Externalities, and Efficient Consumption Taxation, Journal of Public Economics 106, 42-56.

Feldstein, M., (1980) A Contribution to the Theory of Tax Expenditures: The Case of Charitable Giving. In: Aaron, H. J., and M. J. Boskin (Eds.), The Economics of Taxation, Essays in Honor of Joseph Peckman, 99-122. Brookings Institution, Washington, D.C.

Ferrer-i-Carbonell, A., (2005) Income and Well-being: An Empirical Analysis of the Comparison Income Effect. Journal Public Economics 89, 997-1019. 
Galí, J., (1994) Keeping Up with the Joneses: Consumption Externalities, Portfolio Choice and Asset Prices. Journal of Money, Credit, and Banking 26, 1-8.

Glazer, A., K. Konrad, (1996) A Signaling Explanation for Charity. American Economic Review 86, 1019-1028.

Harbaugh, W., (1998a) What do Donations Buy? A Model of Philanthropy Based on Prestige and Warm Glow. Journal of Public Economics 67, 269-284.

Harbaugh, W., (1998b) The Prestige Motive for Making Charitable Transfers. American Economic Review 88, 277-282.

Johansson-Stenman, O., F. Carlsson, D. Daruvala, (2002) Measuring Future Grandparents' Preferences for Equality and Relative Standing. Economic Journal 112, 362-383.

Kaplow, L., (1995) A note on subsidizing gifts. Journal of Public Economics 58, 469-477.

Kaplow, L., (1998) Tax policy and gifts. American Economic Review: Papers and Proceedings 88, 283-288.

Kleven, H., W. Kopczuk, (2011) Transfer program complexity and the takeup of social benefits. American Economic Journal: Economic Policy 3, 54-90.

Layard, R., (1980) Human Satisfaction and Public Policy. Economic Journal 90, 737-750.

Ljungqvist, L., Uhlig, H., (2000) Tax Policy and Aggregate Demand Management Under Catching Up with the Joneses. American Economic Review 90, 356-366.

Moffit, R., (1983) An economic model of welfare stigma, American Economic Review 75, $1023-1035$.

Oswald, A., (1983) Altruism, Jealousy and the Theory of Optimal Non-Linear Taxation. Journal of Public Economics 20, 77-87.

Reinstein, D., G. Riener, (2012) Decomposing Desert and Tangibility Effects in a Charitable Giving Experiment. Experimental Economics 15, 229-240.

Roberts, R.D., (1987) Financing Public Goods. Journal of Political Economy 95, 420-437.

Sen, A.K., (1983) Development: Which Way Now? The Economic Journal 93, 745-762.

Sen, A.K., (1999) Development as Freedom (ed. A. Knopf), New York: Oxford University Press.

Saez, E., (2004) The Optimal Treatment of Tax Expenditures. Journal of Public Economics $88,2657-2684$.

Solnick, S., D. Hemenway, (2005) Are Positional Concerns Stronger in Some Domains than in Others? American Economic Review, papers and proceedings 45, 147-151.

Stiglitz, J.E., (1982) Self-Selection and Pareto Efficient Taxation. Journal of Public Economics 17, 213-240. 
Warr, P., (1982). Pareto optimal redistribution and private charity. Journal of Public Economics 19, 131-138.

Wendner, R., L.H. Goulder, (2008) Status Effects, Public Goods Provision, and the Excess Burden. Journal of Public Economics 92, 1968-1985. 